\title{
STRATEGI KOMUNIKASI DALAM PROSES BHÂKALAN ETNIK MADURA DI DAERAH TAPAL KUDA
}

\author{
Akhmad Haryono \\ Fakultas Ilmu Budaya Universitas Jember \\ email: aharyono.sastra@unej.ac.id
}

\begin{abstract}
Abstrak
Masyarakat etnik Madura (EM) memiliki tradisi budaya bhâkalan (pertunangan) sebelummemasukijenjangperkawinan.Penelitianinibertujuanuntukmendeskripsikan strategi komunikasi yang digunakan oleh warga etnik Madura di daerah Tapal Kuda dalam proses bhâkalan. Metode yang digunakan untuk mencapai tujuan penelitian adalah metode etnografi komunikasi. Data diperoleh melalui observasi partisipasi, wawancara, perekaman, dan studi dokumentasi. Untuk menguji tingkat keabsahan data digunakan trianggulasi. Data yang diperoleh ditranskripsi ke dalam data tertulis dan selanjutnya dianalisis dengan teori-teori pragmatik, stilistika, dan analisis komponen tutur. Penelitian ini menghasilkan temuan bahwa sebagai bentuk strategi komunikasi dalam proses bhâkalan, Pangadâ' (utusan) menggunakan ragam BM È-E, BM È-B sebagai implementasi prinsip kesantunan dan BM Ê-I sebagai strategi untuk mengakrabkan dalam rangka menunjang prinsip kerja sama dengan lawan tutur yang dikenal sudah lama. Gaya retorika tidak langsung berupa bahasa ibarat yang menggunakan ibarat tumbuh-tumbuhan, hewan, dan angin juga digunakan sebagai strategi komunikasi dalam proses bhâkalan.
\end{abstract}

Kata Kunci: etnik Madura, Tapal Kuda, strategi komunikasi

\section{COMMUNICATION STRATEGIES IN THE BHÂKALAN PROCESS BY THE MADURESE ETHNIC GROUP IN THE REGIONOF TAPAL KUDA}

\begin{abstract}
The Madurese ethnic group has a cultural tradition called bhâkalan (engagement), a process prior to one's marriage. This study aims to describe communication strategies by the group in the region of Tapal Kuda in the bhâkalan process. The method used to achieve the research objectives was the ethnography of communication. The data were collected through participant observations, interviews, recording, and documentation study. The data trustworthiness was enhanced by triangulation. The data were transcribed and then analyzed by pragmatic, stylistic and speech component theories. The findings show that regarding communication strategies in the bhâkalan process, a Pangadâ' (messenger) uses a variety of BM E-E, BM Ë-B as the implementation of the politeness principle and BM E $\mathrm{E}-\mathrm{I}$ as a strategy to support the cooperative principle to make the interlocutor who has long been known more intimate. The indirect rhetoric style in the form of metaphors using plants, animals, and wind is also used as a communication strategy in the bhâkalan process.
\end{abstract}

Keywords: Madurese ethnic group, Tapal Kuda, communication strategies 


\section{PENDAHULUAN}

Masyarakat etnik Madura (EM) memiliki tradisi budaya yang unik. Salah satu di antaranya adalah tradisi bhâkalan (pertunangan) sebelum memasuki jenjang perkawinan.Tradisi ini melalui proses yang cukup panjang mulai dari nyarè angin-angin (mencari berita), masang angin-angin (memberi kabar), nylabhâr (melihat si gadis), minta (melamar), dan tompengan (mengikat/ memberi peningset), yang kesemuanya ini merupakan (Wibisono \& Haryono, 2015: 49-50).

Dalam setiap tahapan pada proses bhâkalan tersebut tentu memerlukan bahasa sebagai alat komunikasi. Menurut Aminuddin, (2001: 136), dalam kehidupan manusia bahasa tidak hanya berfungsi sebagai alat komunikasi, melainkan juga menyertai proses berpikir manusia dalam usaha memahami dunia luar, baik secara objektif maupun imajinatif. Oleh karena itu, bahasa selain memiliki fungsi komunikatif, juga memiliki fungsi kognitif dan fungsi emotif. Dengan kata lain, bahasa memiliki banyak fungsi yakni instrumental, regulatori, interaksional, personal, dan informatif, serta mempunyai fungsi hauristik dan imajinatif.

Bahasa merupakan suatu produk sosial dan budaya, bahkan merupakan bagian tak terpisahkan dari kebudayaan itu. sebagai produk sosial dan budaya tentu bahasa merupakan wadah aspirasi sosial, kegiatan dan perilaku masyarakat, wadah penyingkapan budaya termasuk teknologi yang diciptakan oleh masyarakat pemakai bahasa itu. Sudah barang tentu, bahasa sebagai hasil budaya megandung nilai-nilai masyarakat penuturnya (Sumarsono \& Partana, 2002: 20-21; Haryono, 2015:2).
Penggunaan setrategi komunikasi dalam suatu masyarakat tutur cenderung dipengaruhi keseluruhan pola budaya termasuk pemberlakuan status dan kelas sosial, perbedaan umur, gender, serta peran dan jabatan seseorang. Hal ini seiring dengan pernyataan Mulyana \& Rakhmat (2003: 49); bahwa perbedaan status dan kelas sosial bisa menyebabkan timbulnya kesenjangan dalam komunikasi, seperti orang-orang yang berstatus sosial berbeda sulit menyatakan opini secara bebas dan terus terang dalam even diskusi dan perdebatan. Seseorang yang berstatus sosial lebih rendah harus menyatakan rasa hormat kepada orang yang berstatus lebih tinggi.

Untuk itu, penggunaan prinsip kesantunan (politeness principle) prinsip kerjasama (cooperative principle) sebagai bagian setrategi komunikasi perlu mendapat perhatian dalam proses bhâkalan. Grice (1975: 47); Yule (1996: 36-37); Nadar (2009: 24-25) menyatakan bahwa prinsip kerjasama (PK) itu memiliki pengertian sebagai berikut: Buatlah sumbangan percakapan anda sedemikian rupa sesuai yang dikehendaki, sesuai dengan perkembangan konteks atau situasi terjadinya percakapan, dan sesuai dengan maksud atau arah yang disepakati dalam percakapan yang anda ikuti.

Grice selanjutnya merinci PK ke dalam 4 maksim (maxims / guidelines) yaitu, 1) Kualitas (Quality): Pastikan bahwa sumbangan percakapan anda benar, khususnya jangan mengatakan apa yang dianggap anda salah; Jangan mengatakan sesuatu yang tidak didukung bukti yang cukup; 2) Kuantitas (Quantity): Buatlah sumbangan percakapan anda seinformatif mungkin 
sesuai yang diperlukan oleh partisipan tutur-jangan memberikan sumbangan percakapan yang bertele-tele dari pada yang diperlukan; 3) Hubungan/ relevansi (Relation / Relevance): Buatlah percakapan anda relevan dengan konteks tuturan yang sedang dilakukan; 4) Cara (Manner): Bicaralah dengan jelas, dan khususnya, hindari kekaburan dan ketaksaan, serta berbicaralah dengan singkat dan teratur.

Keempat maksim tersebut menjelaskan apa yang harus dilakukan peserta percakapan, agar dia dapat berbicara secara efisien, rasional, dan dilandasi dengan kerjasama, artinya pembicara harus jujur, relevan, dan jelas dengan memberikan informasi secukupnya. Untuk lebih jelasnya kita perhatikan percakapan berikut.

Ada seorang wanita yang sedang duduk pada suatu kursi panjang dipertamanan, dan seekor anjing terbaring di tanah di depan kursi panjang itu. Seorang lelaki datang mendekati dan duduk pada kursi tersebut.

\section{Man : Does your dog bite? \\ Women : No}

(Orang lelaki itu membungkuk untuk mengelus-elus anjing tersebut. Anjing itu menggigit tangan lelaki tersebut)

\section{Man : Ouch! Hey! You said your dog doesn't bite. \\ Women : He doesn't. But that's not my dog. (Yule, 1996: 36)}

Permasalahan dalam percakapan ini bukanlah permasalahan praanggapan (presupposition) karena asumsi 'your dog (the women has a dog)' adalah benar. Wanita tersebut memang mempunyai anjing. Yang menjadi masalah adalah anggapan bahwa pertanyaannya 'Does your dog bite?' dan jawaban wanita itu ' $N o$ ' dimaksudkan tidak berlaku untuk anjing yang terbaring di depannya. Dipandang dari perspektif lelaki tersebut, jawaban wanita itu tidak memberi informasi yang lengkap sebagaimana yang diharapkan. Dengan kata lain, dia (wanita itu) diharapkan memberi jawaban atau informasi seperti dinyatakan dalam kalimat terakhir. Dia tidak memberikan informasi yang lengkap. Hal ini melanggar maksim kuantitas. Dia semestinya tidak hanya berkata ' $N o$ ' terhadap pertanyaan lelaki itu. Akan tetapi,yang terjadi bahwa wanita itu sesungguhnya ingin menunjukkan bahwa dia tidak ingin bercakap-cakap dengan orang asing (orang yang belum dia kenal). Oleh karenanya dia tidak menunjukkan cooperative interaction. Konteks percakapan di atas kurang lengkap informasinya/kurang infonmatif (melanggar maksim kuantitas), sehingga terjadilah salah inferensi dan digigitlah tangan laki-laki tersebut oleh anjing itu. PK memang selalu mendasari setiap percakapan, jika percakapan diharapkan berjalan lancar. Namun demikian, tidak semua maksim berlaku untuk semua situasi-ada kalanya maksim-maksim dalam PK dilanggar untuk memenuhi kebutuhan sosial yang lebih penting.

Berkaitan dengan PK, (Leech, 1993: 120-121; Nadar, 2009: 28-29) mengemukakan bahwa ada masyarakat yang dalam situasi tertentu lebih mementingkan atau mendahulukan prinsip sopan santun (PS) dari pada PK. Lebihlebih dalam masyarakat yang beradab, PS tidak dapat dikesampingkan, tidak dapat dianggap sebagai tambahan ter- 
hadap PK. Selanjutnya Leech (1993: 121-122) memberikan contoh sebagai berikut:

$A$ : We'll all miss Bill and Agatha, won't we?

(Kita semua akan merindukan Bill dan Agatha bukan?)

$B$ : Well, we'll all miss Bill

(Ya, kita semua akan merindukan Bill)

Dalam percakapan tersebut di atas, B dengan jelas melanggar maksim kuantitas: Ketika A menginginkan B mengiakan pendapat A, B hanya mengiakan sebagaian saja, dan tidak menghiraukan bagian terakhir pendapat A. Dari sini kita memperoleh: 'Penutur berpendapat bahwa tidak semua orang merindukan agatha'. Bahwa B sengaja tidak menyatakan pendapat ini, melanggar maksim kuantitas atau maksim kejelasan/kelengkapan informasi, dan maksim hubungan atau relevansi. B lebih mentaati PS dari pada PK karena dia tidak ingin bertindak tidak sopan terhadap pihak ketiga (Agatha).

Politeness juga dapat dilihat dari tingkat tutur yang digunakan dalam komunikasi. Adapun tingkat tutur dalam bahasa Madura menurut penggunaannya dapat diklasifikasikan sebagai berikut.

\section{Tabel 1. Tingkat Tutur BM}

\begin{tabular}{|c|c|c|c|c|c|c|}
\hline \multirow{2}{*}{ No } & \multirow{2}{*}{$\begin{array}{l}\text { Tingkat } \\
\text { Tutur/ } \\
\text { Ragam }\end{array}$} & \multirow{2}{*}{$\begin{array}{l}\text { Hubungan } \\
\text { Partisipan }\end{array}$} & \multirow{2}{*}{ Penggunaan } & \multicolumn{3}{|c|}{ Contoh Pemakaian Kata } \\
\hline & & & & saya & Engkau & ya \\
\hline 1. & $\begin{array}{l}\text { ênjâ'-iyâ } \\
(\hat{\mathrm{E}}-\mathrm{I})\end{array}$ & $\begin{array}{l}\text { sebaya atau penutur } \\
\text { berumur lebih tinggi; } \\
\text { sangat akrab }\end{array}$ & $\begin{array}{l}\text { dengan teman } \\
\text { akrab; orang tua } \\
\text { kepada anak }\end{array}$ & sèngko' & bâ'na & $i y \hat{a}$ \\
\hline 2. & 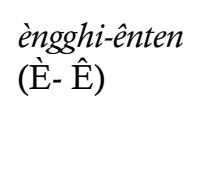 & $\begin{array}{l}\text { penutur berumur } \\
\text { lebih rendah dg jarak } \\
\text { status sosial tidak } \\
\text { terlalu jauh }\end{array}$ & $\begin{array}{l}\text { sesama dewasa yg } \\
\text { baru kenal, kpd } \\
\text { orang tua }\end{array}$ & kaulâ & sampèyan & engghi \\
\hline 3. & $\begin{array}{l}\text { èngghi- } \\
\text { bhunten } \\
\text { (̇̀-B) }\end{array}$ & $\begin{array}{l}\text { penutur berumur } \\
\text { lebih rendah dg } \\
\text { jarak status sosial } \\
\text { cukup jauh; sering } \\
\text { berinteraksi }\end{array}$ & $\begin{array}{l}\text { kpd atasan, kpd } \\
\text { mertua }\end{array}$ & $\begin{array}{c}\text { bhâdhân } \\
\text { kaulâa }\end{array}$ & $\begin{array}{l}\text { panjh } n- \\
\text { nengngan }\end{array}$ & èngghi \\
\hline+4 & $\begin{array}{l}\text { bhâsa alos } \\
\text { (BA1) }\end{array}$ & $\begin{array}{l}\text { penutur dg jarak } \\
\text { status sosial sangat } \\
\text { jauh; jarang } \\
\text { berinteraksi }\end{array}$ & $\begin{array}{l}\text { kpd kiai; kpd } \\
\text { pejabat tinggi }\end{array}$ & $\begin{array}{l}\text { dâl m/ } \\
\text { abdłzina }\end{array}$ & $\begin{array}{l}\text { Ajunan, } \\
\text { padhâna }\end{array}$ & dhâl $m$ \\
\hline+5 . & 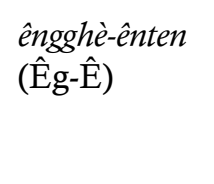 & $\begin{array}{l}\text { penutur berumur } \\
\text { lebih tua; sering } \\
\text { berinteraksi }\end{array}$ & $\begin{array}{l}\text { mertua kpd } \\
\text { menantu, } \\
\text { tetangga yg lebih } \\
\text { muda }\end{array}$ & bulâ & Dhika & engghe \\
\hline+6 & $\begin{array}{l}\text { bhâsa Malaju } \\
\text { (ragam kota) } \\
\text { (BMlj) }\end{array}$ & $\begin{array}{l}\text { agak akrab, tidak ada } \\
\text { hubungan keluarga }\end{array}$ & $\begin{array}{l}\text { teman sekolah } \\
\text { atau kantor, etnik } \\
\text { lain }\end{array}$ & saya & Situ & iya \\
\hline
\end{tabular}


Gaya bahasa merupakan cara memanipulasi unsur-unsur dan kaidahkaidah bahasa untuk memberikan efek tertentu (Asmara, 2015). Style adalah cara yang digunakan seseorang pembicara atau penulis untuk menyatakan maksudnya dengan menggunakan bahasa sebagai sarana. Dengan demikian, style dapat diterjemahkan sebagai gaya bahasa (Ratna, 2009:167). Dengan demikian, dapat dikatakan bahwa gaya bahasa merupakan cara yang digunakan oleh penutur maupun penulis dengan memanipulasi unsur-unsur dan kaidahkaidah kebahasaan untuk memberikan efek tertentu agar tujuan tuturan atau ide-ide penulis dapat tercapai dengan baik.

Diasumsikan bahwa setrategi komunikasi dalam proses bhâkalan dipengaruhi oleh beberapa variabel, antara lain: (1) variabel sosial; (2) psikologis; dan (3) kultur masyarakat etnis Madura. Variabel sosial yang mempengaruhi setrategi komunikasi di kalangan komunitas etnis Madura di daerah Tapal Kuda adalah: (1) perbedaan status sosial; (2) perbedaan umur; dan (3) kedudukan serta peran dalam keluarga. Variabel psikologis yang menentukan setrategi komunikasi antara lain: perasaan enak dan kurang enak. Adapun variabel kultur yang mempengaruhi pola-pola komunikasi adalah faktor tradisi yang sudah lama dipertahankan di kalangan etnik Madura. Fenomena setrategi komunikasi tersebut juga tidak terlepas dari hubungan antarpartisipan tutur sebagaimana pendapat Susanto, (2014: 141); Sukarno (2015: 228) bahwa hubungan antara penutur dan lawan tutur dipengaruhi oleh situasi dan tujuan tutur, serta profesinya.
Berdasarkan alasan-alasan tersebut dapat dirumuskan permasalahan "bagaimanakah stratetgi komunikasi yang digunakan dalam proses bhâkalan?"

\section{METODE}

Pendekatan yang digunakan dalam penelitian ini adalah pendekatan kualitatifdengan fokus kajian Etnografi Komunikasi yakni prosedur penelitian yang menghasilkan data deskriptif yang berupa data tertulis atau lisan dari orang-orang dan perilaku yang dapat diamati.

Data diperoleh dari tiga sumber: pertama (primer) akan digali dari pengamatan secara langsung proses komunikasi komunitas etnis Madura (EM) pada acara bhâkalan di daerah Tapal Kuda; kedua (sekunder) diperoleh dari para orang tua yang sering telibat dalam proses acara bhâkalan; ketiga, informasi dari para tokoh agama dan ilmuwan yang menekuni kajian linguistik dan kajian Madura.Yang dijadikan setting untuk memperoleh data dalam penelitian ini adalah situsi formal dan informaldalam acara bhâkalan.

Observasi partisipasi dilakukan untuk memperoleh data peristiwa komunikasi dengan cara mengamati, mencatat, dan merekam secara langsung data penelitian. Peneliti sambil berpartisipasi dengan mitra tutur berada di tengah-tengah proses dan acara bhakalan. Wawancara dilakukan untuk mendapatkan informasi tentang perilaku komunikasi dan tindak tutur yang digunakan dalam proses bhakalan.

Ada dua teknik yang digunakan untuk menguji keabsahan data yaitu: (1) Trianggulasi, yakni dengan cara membandingkan dua data dari informan yang berbeda, kemudian diambil ke- 
simpulan, apakah kedua data tersebut berbeda atau saling menguatkan satu sama lain; (2) Verivikasi yaitu dengan cara mengadakan pengecekan langsung ke lapangan, apakah data yang sudah didapat sesuai dengan data yang ada dilapangan

Data yang berhasil dikumpulkan melalui observasi partisipasi, catatan lapang, dan alat rekam, ditransikripsikan ke dalam data tertulis secara fonologis. Data yang diperoleh dalam penelitian ini dianalisis secara deskriptif dengan metode analisis wacana dengan konsep pragmatik, dan metode deskriptif. Metode analisis wacana dengan konsep pragmatik PK dan PS (Grice, 1975) dan konsep etnografi komunikasi dengan analisis SPEAKING-grid (Hymes 1964a: 13; Schiffrin, 1994: 141-42) digunakan untuk menganalisis setrategi komunikasi yang digunakan komunitas etnis Madura di daerah Tapal Kuda dalam prosesi acara bhâkalan dengan cara mengadakan analisis secara mendalam terhadap PK dan PS (Grice, 1975: 4158). Adapun metode deskriptif digunakan untuk menjelaskan ragam bahasa yang digunakan oleh komunitas etnis Madura di daerah Tapal Kuda, dengan cara menganalisis perbedaan tingkat tutur (speech level) yang digunakan komunitas etnis Madura dengan mitra tutur dalam prosesi acara bhâkalan.

\section{HASIL DAN PEMBAHASAN}

Masyarakat etnik Madura yang hidup dan menetap di wilayah Tapal Kuda (Jember, Bondowoso, Situbondo, dan sekitarnya) adalah masyarakat migran asal Pulau Madura. Di tempat tinggal mereka yang baru, meskipun dalam beberapa hal mereka sudah terpengaruh oleh derasnya arus globalisa- si dan modernisasi. Namun demikian, adat-istiadat dan tradisi orang Madura di daerah tersebut mirip dengan kebiasaan orang Madura di Pulau Madura. Kemiripan tersebut dapat dilihat dari proses bhâkalan putra-putrinya dari awal sampai akhir.

Bhâkalan atau pertunangan merupakan tahap yang harus dilalui sebelum menuju ke jenjang perkawinan. Pertunangan adalah usaha pendekatan dan penyesuaian antara kedua belah pihak orang tua serta antara anak laki-laki dengan anak gadis sebagai calon pasangan. Bakalan ini dapat terjadi jika kedua belah pihak keluarga sudah sepakat bahwa kedua anaknya akan dinikahkan. Dalam bhâkalan ada beberapa tahapan yang dilalalui yang memerlukan strategi komunikasi yaitu nyarè ngèn-angèn (mencari informasi), nylabhâr(perkenalan), minta (meminta), tumpengan (lamaran).

\section{Strategi Komunikasi dalam Kegiatan Nyarèngèn-angèn}

Sebelum upacara bhâkalan dapat dilangsungkan, kegiatan ini biasanya diawali dengan kegiatan nyarè ngènangèn atau mencari informasi (berita) berkaitan dengan status perempuan yang akan dilamar, apakah perempuan yang akan dilamar benar-benar masih sendiri atau sudah ada pihak lain yang melamar. Kegiatan ini biasanya dilakukan dua tahap. Pertama, dilakukan dengan bertanya ke para tetangga keluarga pihak perempuan atau menanyakan langsung kepada orang yang dianggap mengetahui status perempuan tersebut, yaitu saudara atau sanak famili keluarga pihak perempuan. Jika ternyata dari kegiatan mencari angin tersebut diketahui bahwa pihak perempuan belum ada 
yang meminang, dilakukan kegiatan kedua, yaitu keluarga pihak laki-laki mempertegas mencari informasi lagi tentang status anak perempuan yang akan dilamar. Anak perempuan yang akan dilamar disebut dengan istilah bhâkal atau calon yang akan ditunangkan. Cara memastikannya adalah pihak keluarga laki-laki mengutus seseorang untuk menanyakan langsung kepada orang tua pihak perempuan apakah anak perempuannya belum ada yang meminang. Utusan tersebut berperan sebagai penyampai maksud dan tujuan kedatangannya sebagai wakil keluarga si A. Utusan yang berperan sebagai pencari informasi dan penghubung biasa disebut dengan istilah pangade' (orang yang ada di depan sebagai pendahulu hubungan selanjutnya).

Ragam bahasa yang digunakan untuk berkomunikasi dalam kegiatan nyarè ngèn-angèn kepada tetangga pihak dan orang tua calon perempuan yang ditanyakan statusnya biasanya adalah bahasa Madura ragam èngghi-bhuntên (BM É-B), èngghi-ênten (BM É-Ê), dan ênja'-iyâ ( $\hat{E}-\mathrm{I})$. Penggunaan tingkat tutur (speech level) tersebut dipengruhi oleh tingkat kedekatan hubungan antara Pangadâ' dan keluarga pihak perempuan. Poedjosoedarmo (1979:16-17) menyatakan bahwa penggunaan tingkat tutur sebagai bentuk implementasi politeness (Grice,1975) yang dipengaruhi oleh tingkat formalitas hubungan dan status sosial antarpenutur dan lawan tutur. Hal ini juga berkaitan erat dengan latar belakang sosial buadaya seseorang di dalam masyarakat tutur, sebagaimana dinyatakan (Sukarno, 2015: 228) bahwa Ungkapan kebahasaan dalam komunikasi verbal didasarkan pada la- tar belakang sosial budaya seseorang di dalam masyarakat tutur.

Untuk mencari ngin-angin kepada tetangga pihak perempuan biasanya orang tua pihak laki-laki menugaskan seseorang yang sudah familiar di daerah itu, terutama pangadâ' yang punya teman akrab. Dengan teman yang sudah akrab pangadâ' menggnakan bahasa Madura ragam Ê-I (ngoko) atau É-Ê (madya). Penggunaan ragam bahasa ngoko dan madya tersebut ditujukan untuk menunjukkan suasana keakraban antara kedua belah pihak. Dengan demikian, dapat dikatakan bahwa prinsip-prinsip kesantunan dapat ditinggalkan untuk menumbuhkan suasana keakraban dalam komunikasi. Hal seiring dengan pendapat Nadar (2009:2425) bahwa di dalam situasi komunikasi percakapan anda dibuat sedemikian rupa sesuai yang dikehendaki, sesuai dengan perkembangan konteks (situasi terjadinya percakapan) dan sesuai dengan tujuan dan arah yang disepakati dalam percakapan yang diikuti.

Adapun gaya retorika yang digunakan adalah gaya retorika tidak langsung yaitu berupa bahasa ibarat,seperti pada tuturan berikut ini.

Konteks: tuturan dikemukakan oleh seorang pangad'e' dari pihak calon mempelai laki-laki (P) kepada tetangga calon mempelai perempuan $(\mathrm{T})$. Tuturan berlangsung ketika P melakukan kegiatan ngen-ngangen di rumah $\mathrm{T}$. Tempat bertutur: di teras depan rumah $\mathrm{T}$.

Tuturan 1:

$\mathrm{P}$ : apa jhebbing potrèna pak Haji Ridwan sebelah la bada orèng sè aberri' bin 
sabin? (Apa Gadis putri Pak Haji Ridwan sebelah sudah ada orang yang memberi tanda pengikat).

$\mathrm{T}:$ ghi' tada' (masih belum).

Ragam bahasa Ê-I yang digunakan oleh Pangadâ' tampak pada kosa kata atau frasa apa (apa), la bada (sudah ada), sè aberri' (yang memberi), dan ghi' tada' (masih belum) yang merupakan kosa kode BM Ê-I. Kosa kode tersebut digunakan sebagai bentuk keakraban antara Pangadâ' dan tetangga Haji Ridwan. Adapun ragam BM É-E dan É-B terlihat pada kosa kata potrè (putri) yang digunakan oleh Pangadâ' yang merupakan kosa kode yang digunakan dalam ragam BM É-E dan É-B. Pemakaian kosa kode tersebut sebagai bentuk penggunaan politeness principle (Grice: 1975) kepada pak Haji Ridwan sebagai orang ke 3 (O3) yang memiliki status sosial tinggi di desa itu. Sebagaimana dikatakan Poedjosoedarmo (1979: 32) bahwa penggunaan tingkat tutur juga didasarkan pada status sosial seseorang di masyarakat, walaupun dia tidak terlibat dalam tuturan.

Kata bin-sabin dalam tuturan tersebut yang berarti tanda (bisa berupa daun pepohonan yang diberi warna, tali atau yang lainnya) yang bisanya digunakan petani untuk menandai agar tanamannya tidak diganggu/diambil oleh orang lain. Gaya retorik tidak langsung ini digunakan untuk menanyakan tentang si gadis apakah sudah ada yang mengikat atau memberi peningset sebagai tanda sudah bertunangan. Pada tuturan tersebut jawaban tetangga Haji Ridwan belum ada. Tuturan tersebut menunjukkan bahwa adanya kepatuhan partisipan tutur terhadap prinsip kerjasama
(PK) Grice (1979) sehingga tidak terjadi kesalahpahaman dalam komunikasi.

Setelah mendapat kepastian tentang status si gadis sebagai hasil pelaksanaan ngin-angin dari tetangga, beberapa hari kemudian Pangadâ' atas permintaan pihak laki-laki datang ke rumah pihak perempuan. Mula-mula Pangadâ' mengemukakan maksud kedatangannya ke rumah orang tua pihak perempuan yang akan dilamar, yaitu untuk bersilaturahmi. Selanjutnya, adalah menyampaikan amanah dari orang tua pihak calon laki-laki kepada orang tua pihak calon perempuan, yaitu bermaksud nyarè ngèn-angèn, dengan mengucapkan tuturan seperti yang tertuang dalam petikan berikut.

Konteks: tuturan dikemukakan oleh seorang pangade' dari pihak calon mempelai laki-laki (P) kepada orang tua pihak perempuan (OP). Tuturan dikemukakan ketika $\mathrm{P}$ melakukan kegiatan ngen-ngangen. Tempat bertutur: di ruang tamu orang tua.

Tuturan 2:

$\mathrm{P}$ : Sabelunnah bhâdân kaulâ nyo'on sepora sè langkong rajâ ka panjhênêngan. Sè pertama, bhâdân kaulâ datêng da' ka'dintho silaturakhim dâ' keluarga panjhênêngan. Saterossa, kaulâ narema amanat dari bapak Haji Ridwan kaangguya mastèaghi "Ponapa lêrês jhebbing è kadinto ghi' sobung maghâri?"

(Sebelumnya kami minta maaf kepada Bapak. Yang pertama, kami datang ke kediaman Bapak ini bermaksud ingin menjalin hubungan persaudaraan dengan Bapak. Sete- 
rusnya, kami diutus oleh Bapak Haji Ridwan untuk menanyakan, "Apakah putri Bapak belum ada yang memagari?)

OP: Engghi lêrês belun, mator sakalangkong atas rabuna panjênêngan kaangguy silaturahim da' ka'dinto kalabân tojjuân abhâkta amana dâri Haji Ridwan, (Ya benar belum, Terima kasih atas kedatangan Bapak untuk bersilaturrahmi ke rumah kami dengan tujuan membawa amanah dari Haji Ridwan).

Dalam tuturan tersebut tampak bahwa bahasa yang digunakan oleh $\mathrm{P}$ ketika menanyakan kepada OP "apakah putrinya belum ada yang mengikat?", $\mathrm{P}$ menggunakan gaya retorika tidak langsung yaitu menggunakan bahasa ibarat. $\mathrm{P}$ mengibaratkan seoang gadis yang ditanyakan dengan tumbuh-tumbuhan, sedangkan dipagari diartikan sebagai ikatan pertunangan. Ibarat tersebut dimaksudkan sebagai ungkapan bahwa keperluan dia mendatangi orang tersebut adalah dalam rangka mencari kepastian informasi apakah gadis yang ditanyakan belum ada yang mengikat dalam tali pertunangan. Adapun ragam $\mathrm{BM}$ yang digunakan adalah ragam BM È-B. Penggunaan ragam BM Ė-B (Krama Inggil: bahasa Jawa) menunjukkan adanya hubungan formlitas keduanya (Poedjosoedarmo, 1979).

Di samping mengibaratkan seorang gadis dengan tumbuh-tumbuhan mengibaratkan calon mempelai perempuan juga diibaratkan sebagai hewan piaraan. Dengan gaya retorika tidak langsung, menggunakan gaya perbandingan, pangadâ' calon mempelai laki- laki menanyakan kepada pihak keluarga apakah putrinya sudah ada yang manambatkan. Hal ini seperti tampak dalam petikan data berikut.

Konteks: tuturan dikemukakan oleh seorang utusan pihak calon mempelai laki-laki (P) kepada orang tua calon mempelai perempuan (OP). Tuturan dikemukakan oleh $\mathrm{P}$ ketika melakukan kegiatan ngènangèn. Tempat bertutur: di ruang tamu orang tua.

Tuturan 3:

$\mathrm{P}$ : Ponapa potrè panjhênêngan ampon badha sèmanggher? Manabbi gi' sobhung sèmanggher, bada kacong sè terro daddia keluarga panjênêngan.

(Apakah putri Bapak sudah ada yang mengikat? Apabila belum ada, ada pemuda yang ingin menjadi bagian keluarga Bapak)

Dalam tuturan tersebut tampak bahwa bahasa yang digunakan oleh Pangadâ' sebagai utusan calon mempelai laki-laki dalam menanyakan kepada orang tua pihak calon mempelai perempuan "apakah putrinya belum ada yang mengikat sudah bertunangan" adalah bahasa ibarat. Utusan mengibaratkan seorang gadis yang ditanyakan dengan hewan piaraan, sedangkan tali diartikan sebagai ikatan pertunangan. Ibarat tersebut dimaksudkan sebagai ungkapan bahwa keperluan dia mendatangi orang tersebut adalah untuk mencari tahu apakah gadis yang ditanyakan belum ada yang mengikat dalam tali pertunangan. Melihat kosa kode yang digunakan pada tuturan 3, ragam bahasa yang digunakan adalah BM ragam Ë-B. 
Penggunaan tingkat tutur krama inggil tersebut sebagai bentuk implementasi prinsip kesantunan, karena antara pangadhâ' dan calon besan memiliki hubungan formal.

Gaya retorika lain yang digunakan sebagai sarana untuk menyampaikan keinginan mempertunangkan anak laki-laki dengan anak perempuan seperti tampak pada tuturan berikut.

Konteks: tuturan dikemukakan oleh seorang Pangadâ' (P) kepada orang tua calon mempelai perempuan (OP). Tuturan dikemukakan oleh $\mathrm{P}$ ketika melakukan kegiatan ngènangèn. Tempat bertutur: di ruang tamu orang tua pihak perempuan.

Tuturan 4:

$\mathrm{P}$ : Bâdhân kaulâ mèrêng dari sarêng jhâ' èka'dinto bada kembhang. Tojju'ân kaulâ dâ' ka'dinto, pertama silaturrahmi, sèkapèng duâ'èpon kaulâ dâ' ka'dinto têrro onèngnga bunga kagunganèpon panjenêngan ponapa lêrês ghi' bellun bada sè ngagungè?

(Saya mendengar dari teman kalau di sini ada bunga. Tujuan saya datang ke sini pertama ingin bersilaturahmi, yang kedua adalah ingin menanyakan apakah bunga kepunyaan Bapak sudah ada yang memiliki (meminang) atau belum)?

Dalam tuturan tersebut tampak bahwa bahasa yang digunakan oleh utusan calon mempelai laki-laki dalam menanyakan status anak perempuan kepada orang tua pihak calon mempelai perempuan apakah putrinya belum ada yang mengikat atau melamar adalah bahasa ibarat. Utusan mengibaratkan seoang gadis yang ditanyakan dengan tanaman (bunga). Seorang gadis dibaratkan bunga yang biasanya disenangi seseorang karena bentuk dan warnanya yang cantik dan baunya yang harum. Ibarat tersebut sebagai bentuk retorika untuk mencapai tujuan komunikasi. Sebagai mana pendapat Saville \& Troike (2003: 144) bahwa retorika adalah bahasa yang digunakan untuk tujuan persuasif dalam Bahasa dan budaya tertentu agar tujuan tutur tercapai.

Frasa ghi' bellun bâdâ sè ngagungè (masih belum ada yang memiliki) diartikan bahwa si bunga belum ada yang mengikat tali pertunangan. Tuturan tersebut dimaksudkan sebagai ungkapan bahwa keperluan $\mathrm{P}$ mendatangi $\mathrm{OP}$ tersebut adalah untuk mencari tahu apakah gadis yang ditanyakan benarbenar masih belum bertunangan. Ragam bahasa dilihat dari kosa kode pada tuturan 4 yang digunakan $\mathrm{P}$ adalah BM ragam È-B. Penggunaan BM ragam È-B ini sebagai bentuk setrategi komunikasi $\mathrm{P}$ kepada OP melalui penerapan politeness principle (Grice, 1975; Nadar, 2009) karena adanya formalitas hubungan dari keduanya dan didukung situasi percakapan yang juga formal (Poedjosoedarmo, 1979). Dalam perspektif budaya masyarakat Tapal Kuda pembicaraan tentang proses pertunangan maupun perkawinan dianggap sakral dan formal.

Pertanyaan dalam acara nyarè ngènangèn pihak laki-laki biasanya tidak langsung dijawab oleh orang tua pihak perempuan, kecuali jika kedua calon mempelai sudah saling mengenal satu sama lain dan sudah ada komunikasi dengan para orang tua mereka. Jika di 
antara kedua calon mempelai belum saling mengenal dan di antara kedua orang tua juga belum saling mengetahui lebih dalam, keluarga pihak perempuan memusyawarahkan dengan si gadis dan keluarga besar mereka untuk mempertimbangkan jawaban apa yang akan diberikan.

Dalam rangka mempertimbangkan keputusan yang akan diambil keluarga pihak perempuan biasanya berusaha mencari informasi selengkap mungkin tentang status dan keadaan pihak lakilaki yang menanyakan tersebut. Mereka biasanya secara diam-diam bertanya kepada para tetangga pihak laki-aki. Jika informasi tentang status pihak laki-laki sudah diperoleh dan ada tandatanda bahwa lamaran laki-laki diterima oleh pihak perempuan, biasanya keluarga pihak perempuan mengundang keluarga pihak laki-laki dan anak lakilaki yang akan dijodohkan untuk diajak berkenalan. Perkenalan ditujukan untuk mengetahui lebih dalam keadaan kedua belah pihak. Perkenalan ini biasa disebut dengan istilah nylabhâr (melihat gadis yang akan dipinang).

\section{Strategi komunikasi dalam Nylabhâr}

Pada acara nylabhâr pihak laki-laki, termasuk para pendampingnya, diperkenalkan kepada para kerabat pihak keluarga perempuan. Selain diperkenalkan satu persatu nama kerabat mereka, sesuatu yang diperbincangkan dalam acara inibiasanyaberkisarmenceritakan silsilah keluarga dan kehidupan seharihari. Ragam bahasa yang digunakan sebagai strategi komunikasi dalam acara ini biasanya BM ragam È-B dan É-E. Perihal unik yang terdapat pada acaranya ini adalah cara memperkenalkan atau memperlihatkan calon mempelai perempuan terhadap calon mempelai laki-laki. Jika antara calon mempelai laki-laki dan perempuan belum saling mengenal, mempelai perempuan biasanya tidak ikut bersama keluarga besar menemui calon mempelai laki-laki. Biasanya ia diberi tugas mengeluarkan minuman dan kue-kue untuk dihidangkan kepada para tamu. Pada saat mengeluarkan minuman dan kue untuk hidangan para tamu tersebutlah calon mempelai perempuan diperkenalkan kepada calon bhâkal laki-laki. Pada saat mengeluarkan minuman dan kue ituah calon mempelai laki-laki memperhatikan penampilan dan memandang wajah pihak calon mempelai perempuan. Sebaliknya, pada saat itu juga calon bhâkal perempuan melirik penampilan dan wajah laki-laki yang akan menjadi bhâkal. Sebelumnya, pihak calon mempelai laki-laki sudah diberitahu bahwa perempuan yang mengeluarkan minuman adalah calon bhâkal perempuan. Begitu juga sebaliknya, calon bhâkal perempuan diberi tahu bahwa pemuda yang bertamu saat itu adalah calon bhâkal laki-laki yang ingin melamarnya. Oleh karena itu, calon bhâkal perempuan berdandan sebagus mungkin. Ia biasanya menggunakan pakaian yang paling bagus di antara yang ia miliki, bertingkah laku yang menurutnya paling sopan, dan paling lembut sebagai strategi komunikasi kepada pihak bhâkal laki. Pada acara nylabhâr tersebut yang banyak dinilai oleh kedua belah pihak adalah bahasa non verbal (body language). Biasanya pihak perempuan hanya menyakan pertanyaan yang ringan-ringan, seperti terlihat pada tuturan berikut. 
Konteks: partisipan tutur terdiri dari Pangadâ'(P), orang tua pihak perempuan (OP), dan calon bhâkal laki-laki (BL) Tuturan terjadi di ruang tamu orang tua calon pihak perempuan.

Tuturan:5

$\mathrm{P}$ : Ka'dinto sè asmana Dafir. (Ini Yang namanya Dafir)

OP: Engghi klangkong Rabuna. (Ya, terima kasih kehadirannya)

BL: hanya tersenyum....

OP: Ngabdi è kaemma terakhir, nak Dafir? (Menimba ilmu di mana terakhir?)

BL: È Nurul Jadid Paiton ka'dinto

(Di Pesantren Nurul Jadid Paiton)

Percakapan dalam acara nylabhâr tersebut merupakan percakapan pembuka, karena intinya hanya memperkenalkan antara calon bhâkal laki-laki dengan calon bhâkal perempuan dan pihak keluarga. Yang paling utama dinilai adalah sopan-santun yang diperagakan calon laki-laki selama proses nylabhâr. Sopan santun ini adalah norma interaksi sebagai bagian komponen tutur merupakan hal yang amat penting untuk mendukung pencapaian tujuan komunikasi (Savielle \& Troike, 2003: 110). Prinsip-prinsip kesantunan ini digunakan sebagai strategi komunikasi agar memperoleh kesan yang baik dari pihak perempuan sehingga tujuan nylabhâr tercapai.

Calon bhâkal laki-laki minilai aspek kecantikan dan tingkah laku calon perempuan selama proses mengeluarkan makanan atau minuman. Bahasa yang digunakan $\mathrm{P}$ kepada $\mathrm{OP}$ dan OP kepada $P$ adalah ragam $B M$ È-B. Adapun OP kepada BL mengugunakan ragam $\mathrm{BM}$ É-ÊE, sedangkan $\mathrm{BL}$ kepada
OP menggunakan ragam BM 亡̀-B. Penggunaan ragam BM È-B yang diikuti dengan body language sebagai bentuk strategi komunikasi BL untuk menarik simpati orang tua pihak laki-laki agar dapat menerimanya sebagai calon menantu, jika gadis yang di-slabhâr dianggap cocok.

\section{Strategi Komunikasi dalam Acara Minta}

Setelah acara nylabhâr selesai dan ada tanda-tanda bahwa kedua belah pihak telah saling cocok, dilanjutkan dengan acara minta. Pada acara ini biasanya cukup Pangadâ' yang datang ke rumah pihak perempuan sebagai wakil pihak laki-laki. Strategi komunikasi yang digunakan pada acara ini tuturan langsung ditujukan pada maksud dan tujuan pangadâ' diutus oleh pihak lakilaki, sebagaimana pada konteks tuturan berikut.

Konteks: Partisipan tutur terdiri dari Pangadâ' (P), dan orang tua pihak perempuan (OP), Tuturan terjadi di ruang tamu orang tua calon bhâkalpihak perempuan.

Tuturan 6:

$\mathrm{P}$ : Cangkolang pamator ka'dinto (mohon maaf, permisi mau mengutarakan sesuatu)

OP: Engghi, ngèrèng! (ya, silakan!)

$\mathrm{P}$ : Bâdhânkaulâ narema mandat dari orèng sêppo na' dafir, jhâ' anak ka'dinto têrro dâddiyâ bagian keluarga panjênêngan. Saka'dinto jhughân 
potrèèka'dinto èbâdiyâ ana' sarêng keluarga Haji Ridwan.

(Saya menerima mandat dari orang tua na' Dafir bahwa anak ini ingin menjadi bagian keluarga Bapak. Bagitu juga putri panjênêngan akan dijadikan anak oleh keluarga Haji Ridwan)

OP: Alhamdulillah, ponapa sè daddi maksod sarêng tojjuân Pak Haji Ridwan ngutus panjênêngan, bâdhân kaulâ sarêng kalurga besar narèma kalaban kajêmbhârân.

(Alhamdulillah, apa yang menjadi maksud dan tujuan pak Haji Ridwan mengutus bapak, saya dengan keluarga besar menerima dengan senang hati.)

Pada acara minta ini, biasanya pihak perempuan didampingi oleh keluarga besar, tetapi dalam percakapan cukup diwakili satu orang sebagai wakil keluarga yang dianggap paling berwibawa atau paling sepuh. Dalam situasi yang dianggap formal ini sebagai strategi komunikasi kedua belah pihak menggunakan ragam BM Ë-B sebagai bentuk hormat tuan rumah kepada tamunya, dan tamu kepada keluarga besar tuan rumah. Pada acara minta ini penggunaan politeness principle (PS) dan cooperative principle PK (Grice, 1975: 45-46) yang dirinci kedalam 4 maksim (Quality, Quantity, Relation/Relevance, Manner) dan PS (Prinsip kesantunan dalam berbahasa) (Haryono, 2015: 32) sangat diperhatikan oleh partisipan tutur sehingga tampak tidak ada pelanggaran terhadap PK dan PS dalam tuturan 6 tersebut. Hal tersebut terlihat dari tidak adanya kesalahpahaman antarpartisipan tutur, pengulangan percakapan karena tidak tercapainya tujuan tutur dan diterimanya makasud yang disampaikan Pangadâ' sebagai indikasi tercapainya tujuan komunikasi.

\section{Strategi Komunikasi dalam Acara Tompêngan}

Tompêngan (lamaran) merupakan acara puncak dari serangkaian acara bhâkalan. Pada acara ini keluarga pihak laki-laki datang ke rumah keluarga pihak perempuan. Rombongan biasanya terdiri atas kerabat dekat dan tetangga dekat. Jumlahnya sesuai kesepakatan anatara pangadâ' dan orang tua pihak prempuan yang dibicarakan saat minta. Dalam acara ini biasanya pihak keluarga calon mempelai laki-laki membawa seperangkat pakaian perempuan yang terdiri atas sepotong kain kebaya, sepotong sampèr (kain panjang) atau semacam selendang, sabuk, kerudung, satu set pakaian dalam, sepasang sandal, serta perlengkapan perempuan lainnya (berhias, bersolek atau make up wajah), seperti bedak, pensil alis, lipstick. shampo, sabun, parfum, odol, sikat gigi, dan sisir. Untuk keluarga yang berstatus sosial mampu atau kaya ditambah dengan perhiasan emas, seperti kalung lengkap dengan permata atau liontin, gelang, anting-anting serta cincin sebagai bentuk peningset (pengikat) dalam pertunangan. Pada acara ini calon mempelai laki-laki menyematkan cincin ke tangan calon mempelai perempuan sebagai pertanda bahwa ia telah diikat untuk dijadikan calon istri.

Seperangkat makanan yang dibawa berupa nasi beserta lauk-pauk dan bermacam-macam kue. Duajenis makanan yang selalu ada dalam acara lamaran adalah ketopa' (Jawa: ketupat) dan lêpêt. Ketopa' adalah makanan sejenis lontong 
yang dibungkus dalam daun kelapa muda (janor) dalam bentuk kubus atau jajaran genjang. Lêpêt adalah makanan terbuat dari beras ketan yang dimasak dengan santan dan dibungkus dengan daun kelapa muda dengan bentuk bulat panjang kurang lebih berukuran $15 \mathrm{~cm}$. Menurut para sesepuh ketopak dan lepet merupakan simbol atau harapan bahwa mudah-mudahan jejaka dan gadis yang di-bhâkal-kan tersebut dapat terikat erat satu sama lain dan ikatannya dapat berlanjut ke jenjang perkawinan.

Di samping itu, ketopa' dan lêpêt merupakan isyarat adanya harapan dari keluarga pihak laki-laki akan adanya kunjungan balasan dari pihak keluarga perempuan. Kunjungan balasan pihak perempuan sangat diharapkan oleh pihak keluarga laki-laki, karena pada saat kunjungan tersebut hari dan tanggal perkawinan akan ditentukan oleh kedua belah pihak.

Sesuatu yang tidak boleh tertinggal ketika melamar adalah membawa sèrè pènang (daun sirih dan buah pinang) sebagai bagian dari barang yang dibawa. Dua benda tersebut digunakan sebagai simbol oleh pihak laki-laki bahwa maksud utama kedatangan mereka adalah untuk meminang. Tua dan muda buah pinang yang dibawa memiliki makna simbolis. Jika pinang yang dibawa masih berusia muda, ini berarti bahwa tenggang waktu antara masa pertunangan dan perkawinan relatif masih lama, dapat sebulan, dua bulan atau bahkan satu tahun. Sebaliknya, jika buah pinang yang dibawa relatif sudah tua ini berarti bahwa calon mempelai laki-laki meminta agar masa pertunangan dan upacara perkawinan dipercepat atau jangan lama-lama. Kalau dapat tidak sampai satu bulan. Tuturan yang dikemukakan oleh pangadâ'pihak laki-laki kepada pihak perempuan adalah sebagai berikut.

Konteks: tuturan dikemukakan oleh pangadâ' pihak laki-laki (P) kepada wakil pihak perempuan (PP). Tuturan dikemukakan oleh $\mathrm{P}$ ketika melakukan kegiatan tompengan. Tempat bertutur: di ruamh orang tua pihak perempuan.

\section{Tuturan 7:}

U : Assalamu 'alaikum warahmatullahi wabarakatuh. Cangkolang pamator, bâdhân kaulâ sadhâjâ pertama, dâ' ka tempatka'dintosilaturrahmi, sèkapèng duâ' badi nêrrosagi parêmbhaghân sè kaponkor, èngghi ka'dinto nyambung kaluarga lantaran na'kana' sè dua' neka insyaAllah ampon pada cocok. Moga-moga lantaran pertemuan dua keluarga besar samangkèn ka'dinto èdaddiaghiyâ judubâris dunnya ngatos akhèrat. Pan ponapan sè bakhta ka'dinto comaminagka pangèsto keluarga Haji Ridawan dâ' ajuanan epon keluarga Haji Sofyan. Dâri kadinto anyo'ona tarèma aghi sanaosa tak sesuai sarêng pangarêp tarètan ka'dinto. Cokop saka'dinto pamator badan kaulâ atas nama keluarga Haji Ridwan, manabi bâdâ kakorangan ta' langkong nyo'ona sapora. Wassalamu 'alaikum Warahmatullahi waabarakatuh.

(Assalamu 'alaikum warahmatullahi wabarakatuh. Mohon ijin bicara, Kami pertama-tama ke sini bersilaturahmi, yang kedua ingin meneruskan perbincangan kita yang baru lalu yaitu menyambung keluarga lantaran kedua anak insyaAllah sudah ada kecocokan. 
Semoga berkah pertemuan dua keluarga besar hari ini akan menjadikan keduanya menjadi pasangan di duania sampe akhirat kelak. Sesuatu yang kami bawa hanya sebagai bentuk perhatian keluarga haji Sofyan kepada keluarga Haji Ridwan. Maka dari itu, mohon diterima walaupun tidak sesuai harapan keluarga di sini. Cukup sekian apa yang bisa kami sampaikan, manakala ada kekuarangan kami mohon maaf yang sebesar-besarnya.Wassalamu'alaikum Warahmatullahi waabarakatuh.

PP: Assalamu 'alaikum warahmatullahi wabarakatuh. Nyambung pamator, badan kaulâh atas nama keluarga Haji Ridwan, ngatoragi mator sakaloangkong sè sobung batessa atas rabuna keluarga besar Haji Sofyan da' ka'dinto tempat dalam rangka nyambung sataretanan dua keluarga, mandhâr moghâ na'kana' sè duâ' daddiyâ juduh baris dunnya ngatos akhèrat. Mator sakalangkong jhughân atas pan ponapan sè èbâhkhta keluarga Bondoswoso, moga daddiyâ pangikat silaturrahim antara dua keluarga. Manabi è dalêm acara ka'dinto korang nyam pornaghi tarètan dâri bondowoso atas nama keluarga haji Sofyan anyo'ona sapora sè langkong raja. Manabi ta' kaberrâ'ân, InsyaAllah keluarga ka'dinto têrro jughan nyambunga silaturrahmi da' ka kaluarga bondowoso. Wassalamu'alaikum Warahmatullahi waabarakatuh

(Assalamu 'alaikum warahmatullahi wabarakatuh. Meneruskan apa yang disampaikan perwakilan Haji Sofyan, kami mengucapkan terima kasih yang tiada batasnya atas kedatangan keluarga besar Haji Sofyan dalam rangka menyambung dua keluarga, mudahmudahan kedua anak kita menjadi jodoh di dunia sampai akhirat. Terima kasih juga atas segala sesuatu yang yang dibawa semoga menjadi pengikat silaturrahim anatara dua keluarga. Jika di dalam acara ini ada yang kurang sempurna bagi keluarga dari Bondowoso atas nama keluarga Haji Ridwan mohon maaf yang sebesar-besarnya. Jikalau tidak memberatkan Insya Allah keluarga di sini juga ingin bersilaturahmi kepada keluarga Bondoswoso Wassalamu 'alaikum Warahmatullahi waabarakatuh.)

Tuturan tersebut dibuka dan ditutup dengan salam sebagai tradisi masyarakat Tapal Kuda yang mayoritas pemeluk agama Islam. Frasa Cangkolang pamator (mohon maaf ijin bicara) dalam tuturan tersebut sebagai strategi komunikasi penghormatan dari wakil mempelai laki-laki yang memulai pembicaraan. Dalam acara tompengan biasanya pihak laki-laki yang berbicara lebih dulu karena sekaligus sebagai bentuk penyerahan segala sesuatu yang dibawa keluarga pihak lakilaki yang tersurat pada frasa anyo'ona tarèma aghi (mohon diterima). Begitu pula penyambut yang mewakili keluarga pihak perempuan juga mengawali dan mengakhiri dengan salam. Sebagai pembicara kedua dia menggunakan frasa Nyambung pamator (meneruskan pembicaraan) yang artinya juga sebagai bentuk politeness untuk mengambil alih pembicaraan. Frasa sebagai penerima terlihat pada ngatoragi mator sakaloangkong sè sobung batessa atas rabuna keluar- 
ga besar Haji Ridwan da' ka'dinto tempat dan mator sakalangkong jhughân atas pan ponapan sè èbhâkhta keluarga Bondoswoso (mengucapkan terima kasih yang tiada batasnya atas kedatangan keluarga besar Haji Ridwan dan terima kasih juga atas segala sesuatu yang yang dibawa). Pada data tersebut terlihat kedua belah pihak menggunakan kosa kode È-B sebagai strategi komunikasi yang menunjukkan adanya formalitas hubungan dan situasi tuturan (Poedjosoedarmo, 1979).

Berselang satu minggu kemudian, biasanya rombongan keluarga calon mempelai perempuan mengadakan kunjungan balasan ke rumah pihak keluarga calon mempelai laki-laki. Jumlah rombongan biasanya kurang lebih sama dengan rombongan yang pernah datang ke keluarga pihak perempuan, kadang kala juga lebih banyak karena semua keluarga ingin tahu kondisi keluarga pihak laki-laki. Mereka juga terdiri atas kerabat dan tetangga dekat keluarga calon besan perempuan. Dalam kunjungan balasan tersebut mereka membawa seperangkat pakaian pria dan seperangkat makanan. Pakain pria yang dibawa biasanya berupa sepotong baju, kain celana, sarung, songkok, dan sandal.

Jenis kue khas yang dibawa oleh pihak keluarga calon mempelai perempuan dalam kunjungan balasan ke keluarga pihak laki-laki adalah kue sera$b h i$ atau serabi. Kue serabi terbuat dari tepung beras, santan, gula, dan sedikit garam dan dipanaskan dalam loyang tertutup. Kue serabhi adalah simbol lambang alat kelamin perempuan yang mengandung makna simbolis bahwa rombongan yang datang adalah pihak keluarga calon mempelai perempuan.
Di samping itu, kue khas yang dibawa adalah apem. Kue ini digunakan sebagai bahasa simbol dan harapan mudahmudahan hubungan di antara mereka memeroleh barokah atau berkah dari Tuhan Yang Maha Kuasa. Tuturan yang dikemukakan adalah sebagai berikut.

Konteks: Tuturan pertama dikemukakan oleh orang tua atau Pangadâ' pihak perempuan (PP) kepada keluarga pihak lakilaki. Tuturan kedua dikemukakan oleh Pangadâ' pihak laki-laki (PL). Tempat bertutur: di rumah pihak perempuanpada acara balasan lamaran.

Tuturan 8:

PP: Assalamu 'alaikum warahmatullahi wabarakatuh. Saporana sèlangkong rajha, soalla sè ngèrèng bânnya èpon tak sesuai perjanjian kapongkor, jhughân amè' bada kakalèroanban kacangkolangan sarombongan tan tarètan dari Jember dari awal sampè akhir. Sè è bhâkta keluarga Jember ka'dintoh minangka kembângan, anyo'ona tarèmaaghi kalaban seneng è atè.Dâ' budi dari samngkèn anyo'ona jhâ' sampè ajâ rajâi tèngka dari luar. E bhrâd agi ka'bungka'aan sanaossa bâdâangèn santa', jhâ' sampè èkèbâ ka bâra' ka tèmor. InsyaAlah manabi bungka ka'dinto kokoh ta' sampè' noro' angin, saèngha ponapa sè dhâdhi tojjuan kaulâ sarêng panjênêngan bisa terwujud. Bhân anu pole ka'dinto, karena dâri piha' bâdhân kaulâ ampon aparèng bin sabin da' panjenengan dhâddhi manabi bâdâ sè anangghâlâ'â jhâ' sampè èparèngaghi. Cokop saka'dinto pamator, sala lopot 
nyo'ona sapora. Wassalamu 'alaikum warahmatullahi wabarakatuh.

(Assalamu 'alaikum warahmatullahi wabarakatuh. Kami mohon maaf yang sebesar-besarnya karena yang ikut mengantarkan tidak sesuai perjanjian tempo hari. Kami juga mohon maaf jika kedatangan rombongan kami sejak dari awal sampai akhir berbuat yang tidak berkenan di hati keluarga Bondowoso. Sesuatu yang kami bawa ini hanya sekadarnya, jika tidak dapat memenuhi selera keluarga di sini kami mohon maaf. Kedatangan kami yang penting merupakan pertanda bahwa kami ingin memperkuat hubungan silaturahmi kami dengan keluarga di sini. Oleh karena itu, jika ada angin besar jangan sampai yang kita rencanakan terpengaruh oleh angin tersebut. Agar tujuan kita bersama dapat terlaksana. Jika ada pihak lain yang menginkan putri Bapak mohon juga diberi tahu kalo sudah ada ikatan. Cukup sekian yang bisa saya sampaikan, kuarang le-bihnya mohon maaf yang sebesar-besarnya. Wassalamu 'alaikum warahmatullahi wabarakatuh).

PL: Assalamu 'alaikum warahmatullahi wabarakatuh. Rabuna panjênêngan sè lêbbi benyya' nambâi kajhembaran tor kabhungaan keluarga Jember. Terutama pan ponapan sè èbhakta keluarga Bondowoso menangka pangesto da' kaluarga Jember, bâdân kaulâ narèma kalabân sênêng è pangghaliân. Keluarga Jember jughân sepakat kaangguy ajâgâ hubungan kakeluargaan ka'dinto dri pengaruhpengaruh luar sè bhâkal aganggu dâ' ikatan na' kana' sè duwâ.' Semeoga papanggian è arè samangkèn bisa'a mempererat hubungan kedua keluarga ka'dinto. Cokop saka'dinto sambungan pamator, manabi bada kakorangan baik dalêm pamangghi otaba hidangan nyo'ona sapora sè sobungbetêssa. wassalamu 'alaikum warahmatullahi wabarakatuh.

(Assalamu 'alaikum warahmatullahi wabarakatuh. Kehadiran bapak ibu dan saudara semua yang melebihi perjanjian telah menambah kebahagiaan keluarga Jember. Terutama segala sesuatu yang dibawa oleh keluarga Bondowoso merupakan bentuk perhatian terhadap keluarga Jember. Kami semua menerimanya dengan senang hati. Keluarga Jember juga sepakat untuk menjaga hubungan kekeluargaan ini dari pengaruh-pengaruh luar yang akan mengganggu hubungan ikatan kedua anak kita. Semoga pertemuan di hari ini dapat mempererat hubungan kedua keluarga. Cukup sekian sambutan kami, jika ada kekurangan baik dalam jamuan atau hidangan mohon maaf yang tiada batasnya. Wassalamu 'alaikum warahmatullahi wabarakatuh.)

Sebagaimana biasa dalam acara formal tuturan diawali dengan salam sebagai bentuk pelaksanaan syari'at Islam yang sudah menjadi tradisi warga etnik Madura didaerah Tapal Kuda. Dalam tuturan tersebut tampak bahwa tuturan pertama yang dikemukakan oleh wakil besan pihak perempuan dalam berkomunikasi dengan besan pihak laki-laki adalah meminta maaf kepada keluarga pihak laki-laki jika kedatangan balasan rombongan pihak keluarga 
perempuanmelebihi jumlah yang ditentukan serta memohon maaf atas segala tingkah laku yang kurang berkenan selama berada di keluarga pihak laki-laki. Pihak perempuan juga meminta maaf jika segela sesuatu yang dibawa sebagai oleh-oleh yang diserahkan kepada pihak perempuan tidak memenuhi keinginan keluarga pihak laki-laki. Pernyataanpernyataan tersebut sebagai bentuk retorika untuk mengantisipasi terjadinya pelanggaran terhadap prinsip-prinsip kesantunan dan menjaga keharmonisan hubungan kedua keluarga. Setelah itu, pihak perempuan baru menjelaskan maksud kedatangan mereka yang ingin memperkuat hubungan mereka sampai ke jenjeng pernikahan. Dalam mengemukakan maksud mereka, pihak keluarga perempuan menggunakan bahasa ibarat bahwa meskipun " $E$ bharâd agi ka'bungka'aan sanaossa bâdâ angèn santa', jhâ' sampè èkèbâ ka bâra' ka tèmor. InsyaAlah manabi bungka ka'dinto kokoh ta' sampè' noro' angin, saènggha ponapa sè dhâdhi tojjuan kaulâ sarêng panjênêngan bisa terwujud". Pangadâ' besan perempuan mengibaratkan hubungan yang ingin mereka jalin kokoh seperti pepehononan, meskipun pohon tersebut diterpa angin yang sangat kuat, mereka tetap berharap ranting-rantingnya tidak terbawa angin. Angin di sini bisa diartikan sebagai fitnah, jadi jika ada finah yang sangat kuat kedua keluarga ini harus tetap kokoh hubungan silaturahminya.

Sebagai bentuk penerapan prinsip kerjasa sama dan penghindaran pelanggaran terhadap maksim-makasim grice (1975), Pangadâ' dari pihak laki-laki menjawab satu persatu apa yang disampaikan pagadâ' pihak perempuan. Pada tuturan kedua belah pihak tersebut juga tidak meninggalkan prinsip-prinsip kesantunan. Hal ini terbukti dari penggunaan kosa kode $\mathrm{BM}$ yang digunakan yakni kosa kode È-B.

Dengan demikian, dapat dikatakan bahwa strategi komunikasi yang digunakan oleh pihak laki-laki dan perempuan dalam proses bhâkalan untuk menghindari pelanggaran terhadap PK maupun PS. Penggunaan gaya retorik ibarat tumbuh-tumbuhan, hewan, dan angin yang juga sebagai bagian strategi komunikasi dalam budaya masyarakt etnik Madura dapat dipahami dengan baik. Oleh karenanya, apa yang menjadi maksud dan tujuan kedua belah pihak dapat tercapai dengan baik.

Jika dianalis dengan komponen tutur dalam teori etnografi komunikasi yang dikemukakan Hymes (1964a:13); Schiffrin (1994: 141-42); periksa juga Duranti (1998: 221) yang dikenal dengan 'SPEAKING grid' adalah sebagai berikut:

Situation/Setting (situasi) 'tempat dan suasana' tutur pada acara pertunangan adalah formal sehingga bahasa yang digunakan adalah ragam BM Ė-B. Penggunaan ragam bahasa Krama inggil tersebut juga sebagai strategi komunikasi untuk menghormati partisipan (peserta tutur) yang memiliki hubungan formal. Dengan demikian Ends (akhir) tujuan tutur' dapat diterima dengan baik oleh partisipan tutur. Act sequence (urutan bertindak) 'termasuk alih giliran tutur' didasarkan pada tradisi dan budaya yang sudah menjadi konvensi dalam acara pertunangan. Adapun key (kunci) 'nada tutur' berupa tekanan suara dalam acara pertunangan saling merendah untuk menunjukkan rasa hormat kepada besan yang memiliki hubungan formal. Pada acara pertu- 
nangan tersebut menggunakan instrumen (sarana tutur) berupa sound system agar tujuan tutur tercapai ke semua partisipan tutur yang jumlahnya cukup banyak dan sebagian berada di luar ruang tamu. Norms (norma-norma) 'norma interaksi khususnya prinsip-prinsip kesantunan yang sudah menjadi konvensi dalam budaya masyarakat etnik Madura didaerah Tapal Kuda sangat dipatuhi, lebih-lebih dengan genres 'jenis tuturan' berupa pidato dan percakapan pada acara formal.

Dengan demikian, dapat dikatakan bahwa penggunaan komponen tutur SPEAKING-grid dalam acara bhâkalan (pertunangan) merupakan bagian dari strategi komunikasi untuk memuluskan pencapaian tujuan tutur.

\section{SIMPULAN}

Berdasarkan pembahasan tersebut di atas, dapat disimpulkan sebagai berikut. Pertama, strategi komunikasi yang digunakan dalam proses bhâkalan (nyarè ngin-angin, nylabhâr, minta, dan tompegan/lamaran) selalu berpegang teguh pada prinsip kerjasama (PK) dan prinsip kesantunan (PS) dan komopenen tutur (SPEAKING-grid) dengan gaya retorik ibarat tumbuh-tumbuhan, hewan, dan angin yang didasarkan pada tradisi dan budaya etnik Madura di daerah Tapal Kuda khususnya, dan tradisi serta budaya etnik Madura secara umum. Penggunaan Strategi kemunikasi dalam proses bhâkalan tersebut untuk mencapai tujuan tutur.

Kedua, ragam bahasa yang digunakan untuk berkomunikasi dalam kegiatan proses bhâkalan adalah bahasa Madura ragam èngghi-bhunten (BM È-B), èngghi-enten (BM É-Ê), dan ênja'-iya (BM Ê-I) tergantung konteks tuturan dan tingkat formalitas hubungan antara penutur dan lawan tutur. Untuk partisipan tutur yang memiliki hubungan formal menggunakanragam BM Ë-B sebagai bentuk hormat, sedangakan untuk lawan tutur yang sudah lama dikenal (teman akrab) menggunakan ragam BM Ê-I untuk membangun keakraban antar partisipan tutur.

\section{UCAPAN TERIMA KASIH}

Ucapan terima kasih disampaikan kepada Rektor cq Ketua LP2M Universitas Jember dan Dekan Fakultas FIB Universitas Jember yang telah memberi dukungan sehingga pelaksanaan penelitian dan penyusunan artikel ini dapat berjalan dengan lancar.

\section{DAFTAR PUSTAKA}

Aminuddin, 1995. Stilistika: Pengantar Memahami Bahasa dalam Karya Sastra, Semarang: IKIP Semarang Press.

Asmara, R. 2016. Strategi Kebahasaan Presiden Jokowi dalam Menanamkan Ideologi dan Manifesto Pemerintahan. Litera, Jurnal Penelitian Bahasa, Sastra, dam Pengajarannya. 15(2), 379-388.

Grice, H.P. 1975. Logic and Conversation dalam Cole dan Morgen. Radical Pragmatics. New York: Akademic Press, pp. 41-58.

Duranti, A. 1988. Ethnography of Speaking dalam Newmeyer, Frederick J. Language: The Socio-cultural Context, Volume IV. Linguistics: The Cambridge Survey. Cambridge: Cambridge University Press, PP. 210-228.

Hymes, D. 1964a. "Introduction: Toward Ethnographies of Communication". In American Anthropo- 
ligiest 66. Special Publication: J.J. Gumperz \& D. Hymes. (eds.) The Ethnography of Communication, PP. 1-34 (Part 2)

Leech, G. 1993. The Principle of Pragmatics. Diterjemahkan oleh MDD Oka. Jakarta: UI Press.

Mulyana, D. dan Rakhmat, J. (Ed.). 2003. Komunikasi Antarbudaya Panduan Berkomunikasi dengan Orangorang Berbeda Budaya. Bandung: Remaja Rosdakarya.

Nadar, F.X. 2009. Pragmatik \& Penelitian Pragmatik. Yogyakarta: Graha Ilmu

Poejosoedarmo, S. at al. 1979. Tingkat Tutur bahasa Jawa. Jakarta: DEPDIKBUD.

Ratna, N. K. 2009. Stilistika: Kajian Puitika Bahasa, Sastra, dan Budaya. Yogyakarta: Pustaka Pelajar

Saville-Troike, M. 2003. Ethnography of Communication: an Introduction. New York: Blackwell Publishing Ltd.
Schiffrin, D. 1994. Aproaches To Discourse. Cambridge, Massachusetts 02142 USA: 108 Cowley Road Oxford OX4 1Jf UK.

Sofyan, A. 2016. Bahasa Madura Dialek Sumenep. Yogyakarta: Galang Press.

Sukarno. 2015. Politeness Strategies In Responding To Compliment in Javanese. Indonesian Journal of Applied Linguistics 4(2).pp. 226-236.

Sumarsono, P.\& Partana 2002. Sosiolinguistik. Yogyakarta: SABDA bekerja sama dengan Pustaka Pelajar.

Susanto. 2014. The Paragmatic Meaning of Adress Terms Sampean and Anda.' Indonesian Journal of Applied Linguistics. 4(1).pp. 140-145.

Wibisono, B. \& Haryono, A. 2015. Wacana Perkawinan di Tapal Kuda. Jember: Penerbit Tapal Kuda.

Yule, G. 1996. Pragmatics. Hongkong: Oxford University Press. 